\title{
Empirical fragility assessment after the January 12, 2010 Haiti earthquake
}

\author{
U. Hancilar, F. Taucer \& C. Corbane \\ European Commission, Joint Research Centre, Ispra, Italy
}

\begin{abstract}
In the immediate aftermath of the Haiti earthquake of 12 January 2010, a joint work for the estimation of damage to the building stock based on aerial images was carried out by the United Nations Institute for Training and Research (UNITAR) Operational Satellite Applications Programme (UNOSAT), the European Commission (EC) Joint Research Centre (JRC) and the World Bank/ ImageCAT in support of the Post Disaster Needs Assessment and Recovery Framework (PDNA). A targeted field campaign was led to the areas affected by the disaster in collaboration with the Centre National d'Information Géo-Spatial (CNIGS) representing the Government of Haiti with the purpose of validating the remote sensing based damage assessment. These two methodologies for collecting data resulted in two data sets of the damaged buildings categorised according to European Macroseismic Scale (EMS-98) damage grades. The present study makes use of these data for the derivation of empirical fragility functions. Fragility functions for different urban zones of Haiti, i.e. low-, medium- and high-density built-up zones and shanty zone, are developed from the remote sensing damage assessment data. Structural fragilities for buildings grouped with respect to material type and number of stories are derived on the basis of observed damage data collected through field surveys.

Keywords: empirical fragility, damage assessment, remote sensing, seismic risk reduction.
\end{abstract}

\section{Introduction}

Observed damage data from earthquakes is a valuable source for the estimation of seismic vulnerability of buildings with the purpose of predicting their likely performance in future events. Empirical fragility functions are generated based 
on statistics of observed damage data, traditionally collected by post-earthquake surveys. The use of observational data is the most realistic way to model fragility, as all the variability resulting not only from the structural capacity of the exposed buildings but also in the soil-structure interaction is taken into account. Empirical fragility functions can also serve for validation and calibration of analytically derived fragility curves.

Recent events, e.g. 2010 Chile and Haiti earthquakes, 2009 Samoa earthquake, 2008 Wenchuan earthquake and the 2004 Indian Ocean earthquake, have clearly defined a new direction and paradigm for post-disaster damage assessment: Use of remotely-sensed images/data for the purpose of developing damage and/or fragility models [1]. In the immediate aftermath of the Haiti earthquake of 12 January 2010 that resulted in extensive damage to building structures, there was an unprecedented international effort undertaken by scientists and engineers from all over the world to exploit the newly released remote sensing data for mapping damage and for aiding the recovery efforts [2]. A joint work for the estimation of damage to the building stock based on aerial images was carried out by the United Nations Institute for Training and Research (UNITAR) Operational Satellite Applications Programme (UNOSAT), the European Commission (EC) Joint Research Centre (JRC) and the World Bank/ ImageCAT in support of the Post Disaster Needs Assessment and Recovery Framework (PDNA). A targeted field campaign was also led to the areas affected by the disaster in collaboration with the Centre National d'Information GéoSpatial (CNIGS) representing the Government of Haiti with the purpose of validating the remote sensing based damage assessment. These two methodologies for collecting data resulted in two data sets of the damaged buildings categorised according to EMS-98 [3] damage grades. The reader is referred to Haiti Earthquake-2010 [4] and Corbane et al. [5] for further information.

In the present study, empirical fragility functions are presented: Fragility functions for different urban zones of Haiti, i.e. low-, medium- and high-density built-up zones and shanty zone, developed from the remote sensing damage assessment data and structural fragilities for buildings grouped according to material type and number of stories derived on the basis of observed damage data collected through field surveys. The paper encompasses three sections: description of the data used to derive empirical fragility functions, the methodology used for that purpose and the results and discussions.

\section{Description of the data}

The epicentre of the $M_{w}=7.0$ earthquake that struck Haiti on 12 January 2010 was estimated at a depth of $13 \mathrm{~km}$, close to the town of Léogâne, around $25 \mathrm{~km}$ south-west of the capital Port-au-Prince [6]. Over 220,000 people died in the devastating earthquake, leaving more than 300,000 injured and one million homeless. The earthquake caused extensive damage to buildings throughout the Port-au-Prince region and in the rural areas and towns to the west of the city. Approximately 105,000 residences were completely destroyed and more than 
208,000 buildings were severely damaged. The total value of the damage and losses was estimated at US\$ 7.8 billion, equivalent to the country's GDP in 2009 , being the first time the cost of a disaster is so high compared to the size of a country's economy [13].

Immediately after the catastrophic event, three key international organizations - the World Bank (WB), the United Nations Institute for Training and Research (UNITAR) Operational Satellite Applications Programme (UNOSAT) and the European Commission's Joint Research Centre (JRC) - worked together, in the framework of the joint declaration signed in 2008 between the World Bank, the European Commission and the United Nations Development Group on PostCrisis Assessments and Recovery Planning, to quickly assess damages to the buildings by utilising remotely sensed imagery. A common methodology on the basis of visual interpretation of damage by comparing pre-earthquake satellite imagery to post-earthquake aerial photos was followed. Members of the WBUNOSAT-JRC team in close collaboration with CNIGS (Centre National d'Information Géo-Spatial) also carried out extensive field surveys. For both assessments, the categorization of damage was based on the European Macroseismic Scale (EMS-98) with a five-level grading system: DG-1: Negligible to slight (no structural damage, slight non-structural damage); DG-2: Moderate damage (slight structural damage, moderate non-structural damage); DG-3: Substantial to heavy damage (moderate structural, heavy non-structural damage); DG-4:Very heavy damage (heavy structural damage, very heavy nonstructural damage); DG-5: Destruction (total or near collapse or very heavy structural damage).

This section provides a brief summary of the damage assessment methodology and the adopted damaged building data sets used as input for the fragility analysis. The reader is referred to Corbane et al. [2, 5] and JRC-2010 [8] for detailed descriptions of the data and for further information on the assessment methodology as well as its advantages and limitations.

\subsection{Remote sensing data}

Building-by-building damage assessment was performed by comparing preearthquake satellite imagery from GeoEye and Digitalglobe to post-earthquake aerial photos provided by Google, NOAA-USGS (U.S. Geological Survey) and the World Bank (World Bank-ImageCat-RIT Remote Sensing Mission). The spatial resolution of the satellite imagery was $50 \mathrm{~cm}$ whereas for the aerial photos the resolution was of approximately 15 to $23 \mathrm{~cm}$. Damage grades according to the EMS-98 scale were assigned to individual buildings as a result of detailed point-based damage assessment by computer aided visual interpretation. It should be noted at this point that the types of damage that are recognizable using remotely-sensed data, i.e. nadir imagery, are complete collapses and damage that is evidenced as a shifting of the building footprints, a lack of definition of the perimeter walls, or obvious building debris. Therefore, the damage levels used for marking individual buildings on the aerial photographs were limited to the higher grades of the EMS-98 scale, i.e. substantial to heavy damage (DG-3), very heavy damage (DG-4), and 
destruction (DG-5). However, it should also be pointed out that although damage due to soft-story mechanism would be graded as heavy structural damage, from the analysis of this type of imagery that generally provides an overhead viewpoint such damage is in most cases not detectable. All buildings that did not exhibit visible damage were labelled with "no visible damage".

The extensive work from the remote sensing damage assessment resulted in a data set consisting of about 300,000 buildings distributed throughout 15 different administrative units in Haiti. Land use classes such as agricultural, bare soil, forest, industrial, low-, medium-, high-density built-up zones and shanty zones were provided as an attribute for each assessed building [4]. This allowed reclassifying the data on the basis of two attributes: damage grade versus land use class. For the purpose of earthquake vulnerability assessment, a sub-set of the above described remote sensing based damage data was obtained. Only buildings falling into low-, medium- and high-density built-up zones and shanty zones were considered for the derivation of fragility functions since the distribution of buildings experiencing similar levels of ground motion intensity within the other land use classes was limiting the statistical validity of the data. This reduced the number of buildings to 240,672 . According to this classification a breakdown of the number of buildings is given in Table 1 .

Table 1: Remote sensing data set: number of assessed buildings by land use class and damage grade.

\begin{tabular}{cccccc}
\hline & \multicolumn{4}{c}{ EMS-98 Damage Grades } & \\
\cline { 2 - 5 } & No damage & DG-3 & DG-4 & DG-5 & Total \\
\hline Low-density built-up zone & 1,632 & 135 & 188 & 309 & 2,264 \\
\hline Medium-density built-up & 59,742 & 1,510 & 4,437 & 6,250 & 71,939 \\
\hline High-density built-up zone & 82,893 & 4,272 & 8,867 & 11,263 & 107,295 \\
\hline Shanty zone & 42,263 & 3,652 & 6,448 & 6,811 & 59,174 \\
\hline & & & & & 240,672 \\
\hline
\end{tabular}

\subsection{Field data}

One month after the earthquake, ground surveys were carried out by members of the WB-UNOSAT-JRC team in collaboration with CNIGS in the greater Port-au-Prince area including the communes Carrefour, Petionville, and Delmas, as well as in Gressier and Leogane. The data collected through these surveys were used to validate the results of the joint remote sensing based damage assessment. During the street surveys, data collection forms were utilised where, for each visited building, EMS-98 damage grade, number of stories, construction material type (e.g. reinforced concrete, wooden, steel) and building usage function (e.g. residential, commercial, public, etc.) were recorded. GPS-tagged digital photos were also taken and for some buildings damage classification was made using these photos. 
As a result of the ground observations, data were collected for about 6,400 buildings. Reinforced concrete frames with infill walls (which were termed as 'simple concrete frames-SCF' in the survey forms) constituted about $85 \%$ of the entire data set while $14 \%$ of the surveyed buildings was made of wooden frame with infill walls (which were termed as 'wooden frames-WF' in the survey forms). There were also some buildings, less than $1 \%$ of the total, classified as steel frame. In terms of building use types, the majority of the assessed buildings was residential (81\%), 14\% of them was commercial and the remaining 5\% was identified as public, religious or cultural. In order to obtain a statistically meaningful sampling for fragility analysis, the field data set was sorted with respect to three attribute fields: damage grades, number of stories and construction material. Concerning the number of stories, the buildings are divided into two groups: 1-2 story buildings and 3-5 story buildings, which might be considered as low- and mid-rise buildings, respectively. According to this classification a breakdown of the number of buildings assessed at each damage state is given in Table 2 .

Table 2: $\quad$ Field data set: number of assessed buildings by structural material type, number of stories and damage grade.

\begin{tabular}{|c|c|c|c|c|c|c|c|}
\hline & \multicolumn{6}{|c|}{ EMS-98 Damage Grades } & \multirow[b]{2}{*}{ Total } \\
\hline & No damage & DG-1 & DG-2 & DG-3 & DG-4 & DG-5 & \\
\hline & \multicolumn{6}{|c|}{ Simple Reinforced Concrete Frame } & \\
\hline $1-2$ story & 1,956 & 1,198 & 645 & 496 & 356 & 475 & 5,126 \\
\hline $3-5$ story & 97 & 44 & 40 & 39 & 37 & 88 & 345 \\
\hline \multirow[b]{2}{*}{$1-2$ story } & \multicolumn{6}{|c|}{ Wooden Frame } & \\
\hline & 367 & 163 & 101 & 87 & 78 & 80 & 876 \\
\hline
\end{tabular}

\section{Methodology}

Empirical methods employ damage data from historical earthquakes for the development of fragility functions. The observed damage at various locations can be correlated to instrumental ground motion, intensity, or some measure of intensity [9]. As a result of this statistical process fragility functions are generated. The statistical (or observed) methods are of greater relevance to nonengineered buildings, where substantial damage data are available. The statistical approach offers conceptual simplicity and confidence since it is based on empirical data [10]. By the use of real observational data, all the characteristics of the earthquake event, i.e. source and path information and local soil conditions, as well as the variations in the structural capacity of the exposed buildings are inherently taken into account. Such a data set should consist of sufficient number of data points, should rely on consistent building survey information, and both damaged and undamaged buildings should be included [11]. As described in Sect. 2, remote sensing data was compiled and harmonised 
on the basis of a common assessment methodology and field data was collected using standardised survey forms, thus increasing the homogeneity and consistency of the data sets. The next step following the compilation of building damage data is the characterisation of the corresponding ground motion intensities representing the seismic demand at each of the surveyed buildings. In the forthcoming sections, the representation of the ground motion intensity and the derivation of fragility functions are presented.

\subsection{Ground motion intensity}

Estimates of damage to structures are made on the basis of a given level of ground motion intensity measure. Macroseismic intensity and peak ground motion parameters (e.g. peak ground acceleration, velocity and displacement, PGA, PGV and PGD respectively) have been traditionally used in empirical vulnerability assessment studies [12].

In the case of the Haiti earthquake, no near-field strong ground motions were recorded during the main event. As a result, the ground motion intensity could be inferred from the observed damage or estimated from the earthquake magnitude and distance using ground motion prediction equations. Shortly after the event, the USGS published shaking intensity maps produced by ShakeMap software [13]. ShakeMap generates maps of the spatial distribution of recorded peak ground motion parameters (acceleration, velocity, and spectral response) and of instrumentally derived seismic intensities [14]. The instrumental intensity map is based on a combined regression of recorded peak ground acceleration and velocity amplitudes and relates the recorded ground motion to the Modified Mercalli Intensity (MMI) scale [15]. In the present study, GIS data associated with the PGA, PGV, and MMI shake maps were downloaded from the USGS website (www.earthquake.usgs.gov) and were used as ground motion input in the derivation of fragility functions.

\subsection{Derivation of fragility functions}

The analytical expression of fragility curve is based on the assumption that earthquake damage distribution can be represented by the cumulative standard log-normal distribution function [16]. On such a fragility curve plot, the horizontal axis represents the ground motion intensity measure and the vertical axis refers to the cumulative probability of structural damage reaching or exceeding a given damage state.

For the derivation of fragility functions, building data were spatially combined with ground motion shaking maps in ArcGIS [17] environment. Each of the building data sets, remote sensing and field data, were joined with contours of MMI, PGA and PGV values on the basis of common geographical coordinates, resulting in six maps illustrating the spatial distribution of assessed buildings with respect to the ground shaking intensity distributions. This allowed obtaining pairs of damage grade $(D G)$ versus ground motion intensity measure $(I M)$ for each building. By statistical processing of these pairs, fragility functions from remote sensing data and from field data were derived. 
The methodology given by Shinozuka et al. [18] was followed for the calculation of fragility functions. The parameters of the log-normally distributed fragility functions, i.e. median and standard deviation, were estimated by the maximum likelihood method. The likelihood function is expressed as:

$$
L=\prod_{i=1}^{N}\left[F\left(a_{i}\right)\right]^{x_{i}}\left[1-F\left(a_{i}\right)\right]^{1-x_{i}}
$$

where $F\left(\right.$.) represents the fragility function for a specific damage grade, $a_{i}$ is the value of $I M$ (i.e. MMI, PGA or PGV) to which building $i$ is exposed to, $x_{i}$ takes the value of 0 or 1 depending on whether or not building $i$ experiences the specific damage grade under the given level of $I M\left(\mathrm{MMI} / \mathrm{PGA} / \mathrm{PGV}=\mathrm{a}_{\mathrm{i}}\right)$, and $N$ is the total number of buildings in the data set. Under the current log-normal assumption, $F(a)$ takes the following analytical form:

$$
F(a)=\Phi\left[\frac{\ln \left(\frac{a}{\mu}\right)}{\sigma}\right]
$$

where $\Phi($.$) is the standardized normal distribution function, a$ represents the values of $I M$, and $\mu$ and $\sigma$ are the median and log-normal standard deviation, respectively. These two parameters of the fragility functions were computed by means of the maximum likelihood optimization in Matlab [19]. In this process, proportions of the buildings (observations) being in or exceeding a given damage grade over the ground motion intensity range are obtained by the help of a Boolean vector. This is done by assigning a value of ' 1 ' to buildings experiencing damage equal to or greater than the specified damage grade and, a value of ' 0 ' to buildings with lesser damage than the specified damage grade. The numerical optimization is then performed to maximize the likelihood function, thus obtaining the fragility curve corresponding to the considered level of damage.

\section{Results and discussions}

Fragility functions are in general derived for a specific class of structures for a suite of predefined damage states ranging from slight damage to total destruction. In the present study fragility functions were derived from remote sensing damage assessment data and from field data, for shanty zones and low-, medium- and high-density built-up zones for the first group of data, and for 1-2 story and 3-5 story reinforced concrete buildings and for 1-2 story wooden frame buildings for the second group of data. All fragility curves were obtained for three ground motion intensity measures, MMI, PGA and PGV. The proposed fragilities are valid for the ranges of ground motion severity and damage assessment data specific to the area affected by the main earthquake. 


\subsection{Fragility functions from the remote sensing data set}

MMI-, PGA- and PGV-based fragility curves for low-, medium- and highdensity built-up zones and shanty zones are presented in Figures 1 to 3.
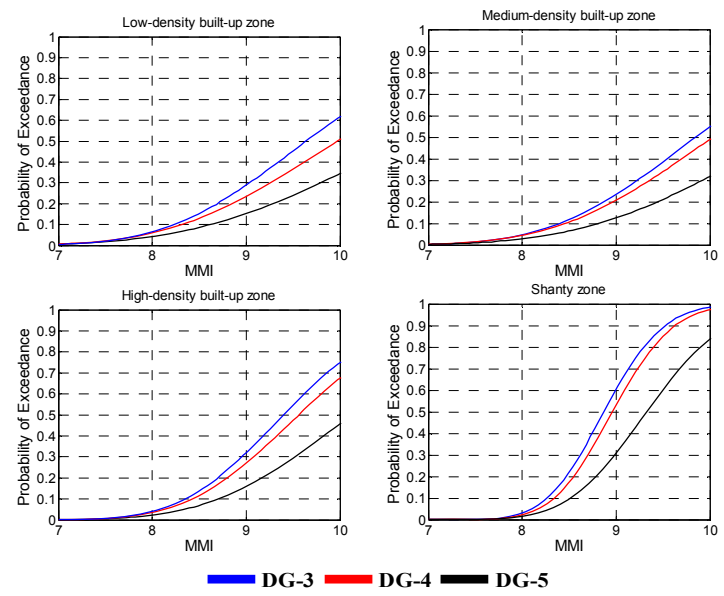

Figure 1: $\quad$ MMI-based fragility curves derived from remote sensing data.
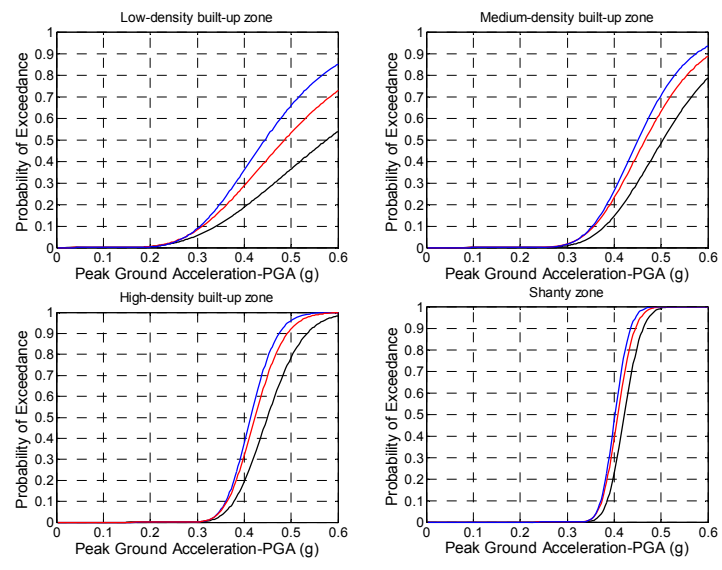

DG-3 DG-4 DG-5

Figure 2: $\quad$ PGA-based fragility curves derived from remote sensing data.

The fragility functions for the three intensity measures suggest that the most vulnerable zone is the shanty zone, followed by the high density built-up zone. The fragility functions of the low- and medium-density built-up zones are quite similar among each other. For all land use classes, the fragility functions are closer to each other for damage grades DG-3 and DG-4. MMI- and PGV-based curves, in general, follow similar patterns, which might be due to the fact that PGV values were directly inferred from MMI values for MMI $>7$ in the 

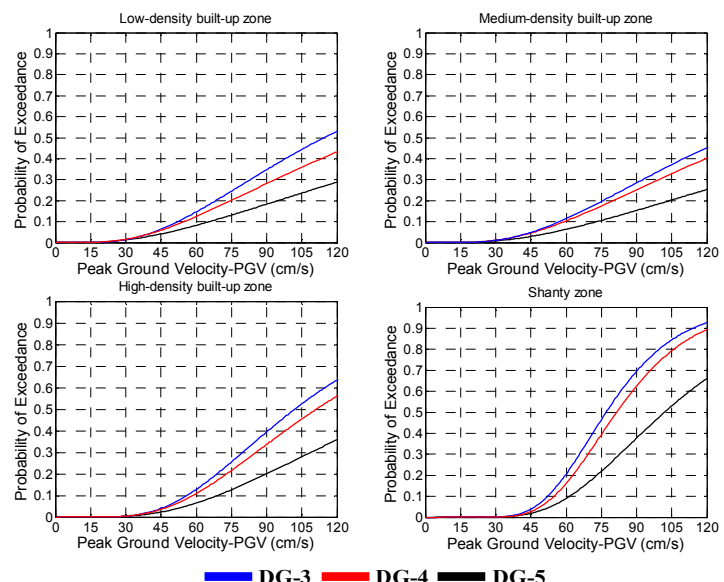

Figure 3: $\quad$ PGV-based fragility curves derived from remote sensing data.

ShakeMap procedure. There is less dispersion in the PGA-based curves, since the distribution of data is limited to a narrow band of PGA values, i.e. $\mathrm{PGA}=0.2 \mathrm{~g}-0.4 \mathrm{~g}$.

\subsection{Fragility functions from the field data set}

MMI-, PGA- and PGV-based fragility curves for reinforced concrete frame and wooden frame buildings are presented in Figures 4 to 6 .
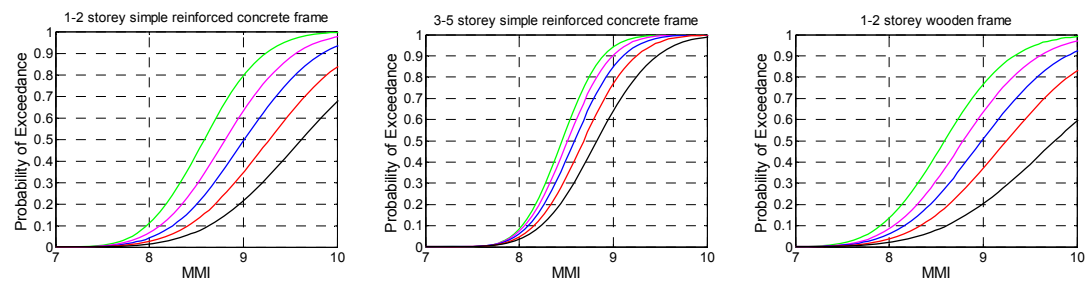

DG-1 $=$ DG-2 DG-3 DG-4 DG-5

Figure 4: $\quad$ MMI-based fragility curves derived from field data.

The fragility functions for the three intensity measures suggest that the most vulnerable building class are 3-5 story reinforced concrete buildings. 1-2 story reinforced concrete buildings perform slightly better than wooden buildings for lower damage states (e.g. DG-1, -2 and even -3). However, the probability of having heavy damage or destruction (e.g. DG-4 and -5) is higher for 1-2 story reinforced concrete buildings than for wooden buildings. Concerning the similar trends for MMI- and PGV-based curves and the lesser dispersion in PGA-based curves, the same can be said as for the remote sensing data set. In addition, PGAbased fragility curves for 3-5 story reinforced concrete buildings give very close exceedance probabilities for different damage grades, thus providing an indication of the brittle failure modes of such buildings. 

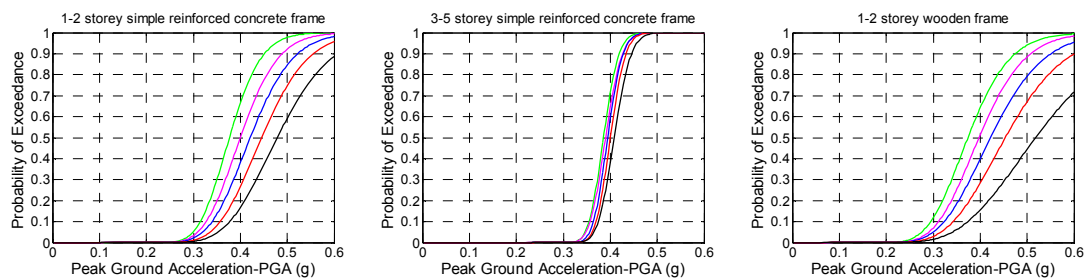

DG-1 D DG-2 DG-3 DG-5 D D D D D D D

Figure 5: $\quad$ PGA-based fragility curves derived from field data.
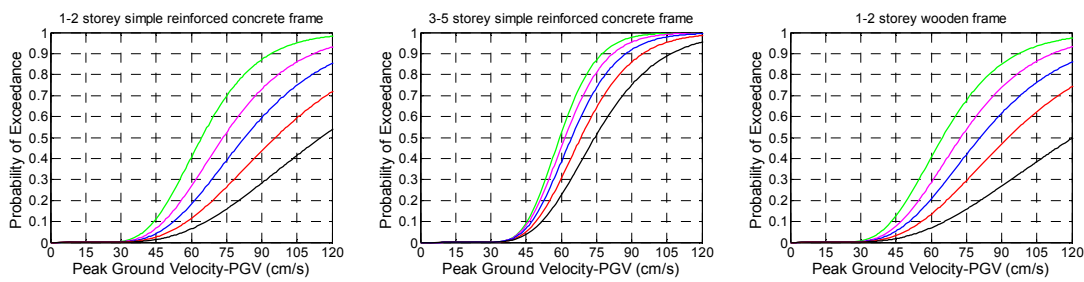

DG-1 2 DG-2 $=$ DG-3 DG-5

Figure 6: $\quad$ PGV-based fragility curves derived from field data.

Interpretations of the proposed fragilities are also in line with the observations of other post-earthquake field reconnaissance teams. Eberhard et al. [20] and Fierro and Perry [21] reported that the performance of reinforced concrete frames with concrete block masonry infill was particularly poor and buildings with light roofs (timber or sheet metal) performed better compared to buildings with concrete roofs and slabs. Taucer et al. [22] observed that reinforced concrete buildings showed either very high or slight damage, with few buildings having formed plastic hinges at beam ends, suggesting a brittle failure mode for most buildings. There is common agreement from the observation of the different site survey teams that the main reason for the widespread of damage to residential, commercial and government buildings was the absence of earthquake-resistant design. They concluded that, in many cases, the structural types, member dimensions, and seismic detailing were inadequate to resist the strong ground motions experienced during the main event and that these deficiencies might have been exacerbated by poor construction practices.

\section{Conclusions}

Two sets of empirical fragility functions derived from two separate sets of damage assessment data gathered after the 12 January 2010 Haiti earthquake have been presented. The first set, from remote sensing, allowed constructing fragility functions on the basis of land use classes, while the second set, based on field data, allowed deriving fragility curves for different building typologies classified in terms of material type and number of stories. Each data source has inherent advantages and disadvantages. Field data provide detailed information 
on the characteristics of the exposed buildings at all levels of damage, e.g. slight, moderate, heavy, collapse; however, the number of surveyed buildings is limited to the availability of on-site human resources. Much more buildings can be assessed by computer aided visual interpretation of remote sensing imagery in a shorter time, however, it only allows identifying non-damaged, heavily damaged and collapsed buildings, and buildings belonging to land use classes. Further work for the estimation of building heights and building type from remote sensing imagery is underway, which can potentially provide useful information for the calibration of field data-based fragility functions.

The derived fragility functions show that the most vulnerable urban zone is the shanty zone, followed by the high density built-up zone and, that the most vulnerable building class are 3-5 story reinforced concrete buildings. The proposed fragility functions can be useful for rapid damage/loss assessments in future events and can provide a preliminary basis for the development of earthquake loss models for Haiti and the Caribbean region. They can also contribute to global databases and studies such as the Supersites by the Group of Earth Observation (GEO) [23] and the Caribbean Regional Programme by the Global Earthquake Model (GEM) [23].

\section{References}

[1] RS-8 2010: Workshop summary and resolutions. The $8^{\text {th }}$ International Workshop on Remote Sensing for Disaster Management, 2010, Tokyo, Japan. http://mceer.buffalo.edu/publications/workshop/RS-8/00Workshop Resolutions.pdf. Last access: 15.08.2011.

[2] Corbane C, Carrion D, Lemoine G, Broglia M. Comparison of damage assessment maps derived from very high spatial resolution satellite and airborne imagery produced for the Haiti 2010 earthquake. Earthq Spectra 2011a; 27(S1): 199-218.

[3] Grünthal G (editor). European Macroseismic Scale 1998 (EMS-98). In: Cahiers du Centre Européen de Géodynamique et de Séismologie, v. 15, 1998, Luxembourg.

[4] Haiti Earthquake 2010: Remote Sensing based Building Damage Assessment Data. http://www.unitar.org/unosat/haiti-earthquake-2010remote-sensing-based-building-damage-assessment-data

[5] Corbane C, Saito K, Dell'Oro L, Gill SPD, Piard BE, Huyck CK, Kemper T, Lemoine G, Spence RJS, Shankar R, Senegas O, Ghesquiere F, Lallemant D, Evans GB, Gartley RA, Toro J, Ghosh S, Svekla WD, Adams BJ, Eguchi RT. A comprehensive analysis of building damage in the January 12, 2010 Mw7 Haiti Earthquake using high-resolution satellite and aerial imagery. Photogrammetric Engineering \& Remote Sensing 2011b; 77(10): 997-1009.

[6] USGS (2010): http://earthquake.usgs.gov/earthquakes/recenteqsww/Quakes us2010rja6.php\#details 
[7] Haiti PDNA (2010) - Haiti Earthquake Post Disaster Needs Assessment: Assessment of damage, losses, general and sectoral needs. Annex to the Action Plan for National Recovery and Development of Haiti.

[8] JRC (2010): Building damage assessment report: Haiti earthquake 12 January 2010, Joint damage assessment. JRC Scientific and Technical Report, Ispra, Italy.

[9] Spence R, Coburn A, Pomonis A. Correlation of ground motion with building damage: the definition of a new damage-based seismic intensity scale. In: Proceedings of the $10^{\text {th }}$ World Conference on Earthquake Engineering, 1992, Rotterdam, Netherlands.

[10] Erdik M, Sesetyan K, Demircioglu MB, Hancilar U, Zulfikar C. Rapid earthquake loss assessment after damaging earthquakes. Soil Dyn Earthq Eng 2011; 31: 247-266.

[11] Sarabandi P, Pachakis D, King SA, Kiremidjian AS. Empirical fragility functions from recent earthquakes. In: Proceedings of the $13^{\text {th }}$ World Conference on Earthquake Engineering, 2004 Vancouver, Canada.

[12] Calvi GM, Pinho R, Magenes G, Bommer JJ, Restrepo-Vélez LF, Crowley H. Development of seismic vulnerability assessment methodologies over the past 30 years. ISET Journal of Earthquake Technology 2006; 43(3): 75104.

[13] ShakeMap 2011: ShakeMap Scientific Background, http://earthquake.usgs.gov/earthquakes/shakemap/background.php\#wald99a

[14] Wald DJ, Worden BC, Quitoriano V, Pankow KL. ShakeMap manual: technical manual, user's guide, and software guide. U.S. Geological Survey Techniques and Methods 2005, Book 12, Section A, Chap. 1. Reston, Virginia, U.S. Geological Survey: 132.

[15] Wood HO and Neumann F. Modified Mercalli Intensity Scale of 1931. Bull of the Seismological Society of America 1931; 21(4): 277-283.

[16] Kircher CA, Nassar AA, Kustu O, Holmes WT. Development of building damage functions for earthquake loss estimation. Earthq. Spectra 1997; 13(4): 663-682.

[17] ESRI 2010: ArcView, ArcMap 10.0, ESRI Inc., 2010.

[18] Shinozuka M, Feng MQ, Lee J, Naganuma T. Statistical analysis of fragility curves. Journal of Engineering Mechanics (ASCE) 2000; 126(12): 12241231.

[19] MathWorks 2008: MATLAB v7.7.0, The Language of Technical Computing, the MathWorks Inc., 2008, USA.

[20] Eberhard MO, Baldridge S, Marshall J, Mooney W, Rix GJ. The MW 7.0 Haiti earthquake of January 12, 2010; USGS/EERI Advance Reconnaissance Team Report, 2010, U.S. Geological Survey Open-File Report 2010-1048, 58 p. http://pubs.usgs.gov/of/2010/1048/

[21] Fierro E and Perry C. Preliminary Reconnaissance Report - 12 January 2010 Haiti earthquake. PEER Report 2010, University of California, Berkeley, USA. http://supersites.earthobservations.org/Haiti Reconnaissance.pdf 
[22] Taucer F, Corbane C, Gerhardinger A. Haiti Earthquake of 12 January 2010: Field Damage Assessment, Data Collection and Analysis. In: Proceedings of Sismica $2010-8^{\circ}$ Congresso de Sismologia e Engenharia Sismica, 2010, University of Aveiro, Portugal.

[23] The Supersites of the Group of Earth Observation (GEO): http://supersites.earthobservations.org/haiti.php

[24] The Caribbean Regional Programme of the Global Earthquake Model (GEM): http://www.globalquakemodel.org/regional-programmes/caribbean 